\title{
Pemahaman Pelaku Desain Residensial Bertingkat Tinggi pada Performance-Based Building Design (PBBD) di Surabaya.
}

\author{
Sulfiah Dwi Astarini ${ }^{1, *}$, Christiono Utomo ${ }^{1}$ \\ Departemen Teknik Sipil, Institut Teknologi Sepuluh Nopember, Surabaya ${ }^{1}$ \\ Koresponden*, Email: sulfiahdwiastarini@gmail.com
}

\begin{tabular}{lll}
\hline & Info Artikel & Abstract \\
\hline Diajukan & 9 Februari 2021 & Residential property development is inseverable from the growing demand for residential in \\
Diperbaiki & 23 April 2021 & Surabaya. To meet this demand, high-rise residential was demanded to be able needs of the \\
Disetujui & user. This can be do while the design process. However, the design process is often a \\
& measurable failure during construction, and will impact of user satisfaction on the post \\
& occupancy. Performance-Based Building Design (PBBD) discusses the building performance \\
& that can be determined at the beginning since the building in the phase of design, so this study \\
& aims to determine the designer's knowledge of the PBBD concept. With the knowledge of \\
& PBBD, the design team can increase innovation by articulating the performance of the \\
& building results in fulfiling more effective and efficient performance requirements. In addition, \\
& the designer can consider more perspectives, because it involves several of disciplines, and \\
& design that are created, translated and integrated according to the needs of end user building. \\
& This study used survey method with the questionnaire as data tool collection, which is \\
& distributed to designer in Surabaya. From the data collection, 42,65\% of designer have known \\
& the PBBD concept, 19,12\% of the designer don't know about the concept, respondents who \\
know and use it in the design process amount to 22.06\% and only 16,18\% know the PBBD but & have not used it the design process.
\end{tabular}

\begin{abstract}
Abstrak
Pembangunan properti residensial tidak lepas dari permintaan akan hunian yang terus berkembang di kota Surabaya. Guna memenuhi permintaan tersebut, residensial bertingkat tinggi dituntut agar sesuai dengan kebutuhan pengguna. Hal ini dapat dilakukan pada saat proses desain. Namun proses desain sering terjadi kegagalan yang terukur pada saat konstruksi, sehingga berimbas kepada kepuasan pengguna pada masa pasca huni. Performance-Based Building Design (PBBD) membahas mengenai kinerja bangunan yang dapat ditentukan di awal sejak bangunan tersebut dalam tahap desain, sehingga penelitian ini bertujuan untuk mengetahui pemahaman pelaku desain terhadap konsep PBBD. Dengan pemahaman terhadap PBBD, tim desain dapat meningkatkan inovasi dengan mengartikulasikan hasil kinerja bangunan dalam memenuhi kinerja secara efektif dan efisien. Selain itu pelaku desain juga dapat mempertimbangkan lebih banyak perspektif karena melibatkan berbagai disiplin ilmu, serta desain yang dibuat, diterjemahkan dan diintegrasikan sesuai dengan kebutuhan pengguna akhir bangunan. Metode yang digunakan pada penelitian ini yaitu survei berupa kuesioner sebagai alat pengumpulan data, yang dibagikan kepada pelaku desain di kota Surabaya. Dari pengumpulan data tersebut dihasilkan sebanyak $42,65 \%$ pelaku desain mengetahui konsep PBBD, sebesar $19,12 \%$ pelaku desain yang belum mengetahui konsep tersebut, responden yang mengetahui dan menggunakannya dalam proses desain sebesar $22,06 \%$ dan $16,18 \%$ yang mengetahui PBBD namun belum menggu-
nakannya dalam proses desain. nakannya dalam proses desain.
\end{abstract}

Kata kunci: properti, residensial bertingkat tinggi, desain bangunan berbasis kinerja.

\section{Pendahuluan}

Permintaan hunian yang terus bertambah namun lahan permukiman yang terbatas terkhususnya di kota-kota besar seperti Surabaya, mengakibatkan terjadinya peningkatan pembangunan gedung residensial bertingkat tinggi. Hal ini juga didorong karena perubahan gaya hidup masyarakat modern yang ingin memiliki hunian di tengah pusat kota.

Namun, bertambahnya properti residensial yang terjadi tentunya tidak selalu berjalan dengan baik, mulai dari tahap merencanakan, mendesain, mengkoordinasi dan membangun sebuah bangunan melibatkan seluruh professional konstruksi. Ketika merancang bangunan bertingkat tinggi, salah satu tujuan kinerja bangunan yang harus dipertimbangkan adalah kenyamanan pengguna akhir sebuah bangunan [1]. Oleh karena itu penting untuk merencanakan tujuan kinerja sejak awal proses desain.

Tahapan desain adalah fase yang paling singkat dibandingkan dengan fase konstruksi dan fase operasional. Pada 
fase desain, perancang sebagai pelaku desain berperan penting dalam pengendalian strategi pekerjaan. Kegagalan perancang dalam mengelola desain akan berimplikasi ke fase proyek selanjutnya. Sebagai contoh, apabila terjadinya kekurangan data dalam gambar maupun dokumen desain mengakibatkan adanya perubahan konstruksi sebesar 50\% [2]. Selain itu sebanyak tiga perempat proyek yang mengalami perbaikan desain, juga mengakibatkan adanya pertambahan biaya dan melebihi waktu dari yang ditargetkan [3]. Di sisi lain, terjadinya kegagalan penentuan kinerja bangunan sejak awal desain juga akan mengakibatkan kegagalan prematur pada bangunan, dan ketidakmampuan untuk menilai kinerja bangunan yang berkelanjutan [4].

Mengatasi permasalahan tersebut diperlukan suatu konsep dalam menyatukan berbagai macam pihak yang terlibat untuk berbagi informasi serta pengetahuan agar mencapai tujuan bersama sesuai dengan yang diharapkan. Performance-based Building Design (PBBD) adalah konsep yang digunakan untuk merancang dan membangun gedung dengan kinerja tinggi, dimana prosesnya membutuhkan berbagai ahli desain yang dapat menerjemahkan kriteria kinerja sesuai dengan kebutuhan pengguna akhir [5]. Dalam proses ini, keterlibatan perancang dibutuhkan untuk secara efektif berkolaborasi dalam mengelola penyelesaian tugas desain [6]. Karena kompleksitas pekerjaan desain yang memiliki kriteria kinerja sebagai tujuan akhir pencapaian proyek, pendekatan PBBD memungkinkan pencapaian desain terbaik karena penggunaan evaluasi desain yang dilakukan menggunakan teknik pengoptimalan [7]. Beberapa manfaat penggunaan konsep PBBD yaitu: 1) meningkatkan inovasi desain; 2) mendorong kemampuan integritas objek dan partisipan selama desain; serta 3) memungkinkan pengurangan risiko selama siklus hidup bangunan [8].

Contoh PBBD seperti yang diteliti oleh [9] dalam merancang bangunan berdasarkan kinerja teknikal yakni berkaitan dengan keamanan dan keselamatan penghuni. Bangunan yang dirancang berbasis kinerja harus mampu melindungi pengguna/ penghuni dari bahaya seperti gempa bumi, badai angin, kebakaran, dll. Tidak hanya bangunan yang aman, PBBD juga menyediakan bangunan ramah lingkungan berdasarkan kriteria kinerja lingkungan, seperti pada penelitian [4] yang mengembangkan desain berkelanjutan untuk bangunan residensial, hal ini berguna untuk mengurangi emisi karbon dan meminimalkan konsumsi energi yang dihasilkan oleh gedung hunian.

Berdasarkan latar belakang tersebut, ini menjadi dasar tujuan penelitian yaitu untuk mengetahui pemahaman pelaku desain terhadap konsep PBBD pada properti residensial bertingkat tinggi di kota Surabaya.

\section{Metode}

Ada banyak metode yang digunakan pada penelitian terdahulu mengenai PBBD, diantaranya adalah kajian literatur [5], [7], metode survey [4], [10], penggunaan IT model [1], [11], dan studi kasus [12], [13].

Metode yang digunakan dalam penelitian ini yaitu dengan menggunakan alat instrumen data berupa survei kuisioner, dengan teknik pengambilan sampel yang dilakukan adalah purposive sampling. Purposive sampling merupakan teknik pengambilan data dengan menentukan kriteria khusus [14]. Karena penelitian ini berfokus pada desain proyek, maka responden yang sesuai dan ahli dibidang tersebut adalah desainer arsitek, engineer teknik yang meliputi struktur dan mekanikal yang memiliki pengalaman atau yang sedang terlibat dalam proses desain residensial bertingkat tinggi di kota Surabaya.

Untuk memudahkan peneliti dalam melakukan pencarian terhadap perusahaan konsultan desain di kota Surabaya, maka pencarian dilakukan pada perusahaan yang terdaftar dalam organisasi Ikatan Nasional Konsultan Indonesia (INKINDO) dan organisasi Ikatan Arsitek Indonesia (IAI). Sebelum mengirimkan alat instrumen penelitian, terlebih dahulu perusahaan-perusahaan konsultan desain tersebut dihubungi untuk mengkonfirmasi kesediaan pelaku desain didalam perusahaan yang dimaksud untuk dapat terlibat dalam penelitian ini. Setelah perusahaan tersebut menyatakan kesediaannya untuk berpartisipasi, kuisioner kemudian dikirimkan ke perusahaan terkait yang dilengkapi dengan amplop balasan. Responden diberikan waktu \pm 2 minggu untuk memberikan tanggapannya terhadap isian kuisioner. Hasil survei selanjutnya dikumpulkan dan dianalisa dengan menggunakan deskriptif kuantitatif.

\section{Hasil dan Pembahasan}

Penyebaran data dilakukan terhadap pelaku desain di Surabaya dengan total 245 kuisioner yang dibagikan kepada sampel. Sebanyak 85 kuisioner yang berhasil dikumpulkan dan dapat dianalisis lebih lanjut.

Berdasarkan hasil survei dari penelitian ini, Tabel 1 menunjukkan karakteristik responden penelitian berdasarkan pengalaman dalam mendesain bangunan properti residensial bertingkat tinggi di kota Surabaya. Perancang yang terlibat dalam penelitian mayoritas memiliki pengalaman 3 tahun. Hasil penelitian selanjutnya di bahas lebih lanjut.

Untuk menggali pemahaman responden terhadap konsep PBBD yang diterapkan pada proses desain, responden diminta untuk mengisi dua pernyataan indikator. Indikator pertama yaitu indikator pemahaman, dan indikator kedua yaitu pertanyaan penerapan PBBD pada proses desain. 
Tabel 1. Karakteristik Pengalaman Responden

\begin{tabular}{|c|c|}
\hline Pengalaman Responden & Presentase \\
\hline$<1$ & $27 \%$ \\
\hline $1-3$ & $35 \%$ \\
\hline $3-5$ & $16 \%$ \\
\hline $5-10$ & $13 \%$ \\
\hline $10-15$ & $9 \%$ \\
\hline
\end{tabular}

Indikator pertama yaitu indikator pemahaman, meminta responden untuk memberikan tanggapannya terkait dengan pertanyaan mengenai pemahaman terhadap PBBD yaitu dengan memilih jawaban isian kuisioner 'belum mengetahui' hingga 'mengetahui dan menggunakan PBBD pada proses desain'. Untuk indikator kedua yaitu penerapan PBBD pada proses desain, responden diminta untuk memberikan tanggapannya dengan membubuhi tanda $(\sqrt{ })$ pada pertanyaanpertanyaan penelitian berdasarkan pemahaman responden terhadap konsep PBBD yang diterapkan oleh pelaku desain selama proses kegiatan desain. Responden yang memilih 'belum mengetahui' pada indikator 1 tidak diperkenankan untuk mengisi pernyataan pada indikator 2 . Hasil penelitian kemudian ditunjukkan pada Gambar 1.

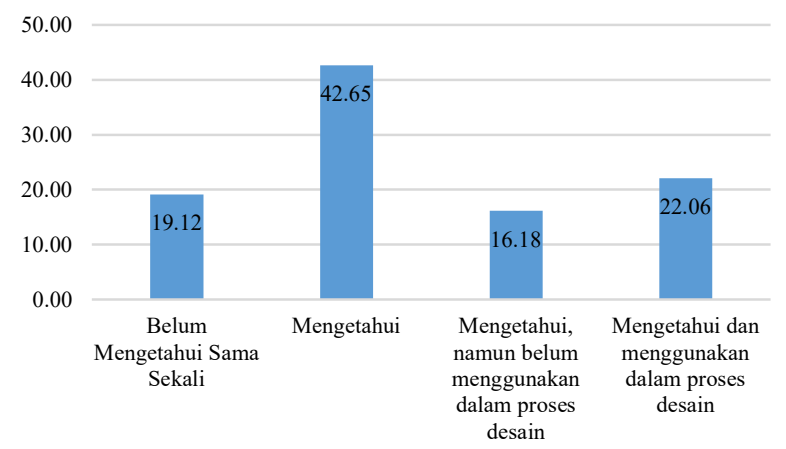

Gambar 1. Pemahaman responden terhadap PBBD

Hasil penelitian ini menemukan bahwa sebahagian dari pelaku desain belum mengetahui konsep PBBD dengan perolehan persentase sebesar 19,12\%. Dari hasil tersebut dipahami bahwa meskipun konsep PBBD bukanlah hal yang baru dalam proses desain, namun nyatanya pendekatan ini belum banyak diketahui oleh pelaku desain di kota Surabaya. Padahal, pentingnya pemahaman perancang terhadap PBBD memungkinkan perancang dapat merangsang inovasi selama proses kolaborasi yang dilakukan agar desain yang dihasilkan terintegrasi dengan baik dan kriteria kinerja yang telah direncanakan dapat dipenuhi oleh bangunan [15].
Hal lain yang dipahami dalam penemuan ini adalah responden yang belum mengetahui konsep PBBD, kemungkinan dari mereka tidak menyadari bahwa mereka telah menerapkan pendekatan tersebut dalam proses desain, apalagi saat ini perancangan bangunan telah mulai beralih ke bangunan hijau dan bangunan berkelanjutan yang merupakan bagian dari bangunan berkinerja tinggi [16]. Hasil penelitian yang ditemukan ini menjadi suatu permasalahan yang muncul. Meski demikian, penelitian ini juga menunjukkan bahwa mayoritas responden mengetahui konsep PBBD didapatkan perolehan persentase sebesar $42,65 \%$. Masih terdapat celah terhadap pemahaman dan penerapan mengenai konsep PBBD diantara perancang. Dalam hal ini, meskipun perancang mengetahui konsep PBBD, namun pada praktiknya pendekatan ini masih belum digunakan dalam desain oleh beberapa pelaku desain (16,18\%). Kemungkinan ini disebabkan oleh karena konsultan desain harus tetap menyesuaikan persyaratan yang diminta oleh owner, terlebih untuk owner yang bertindak sebagai pengusaha properti, yang biasanya tidak terlalu menekankan kinerja kenyamanan penghuni pada bangunan [5]. Adapun responden yang memberikan tanggapan positif yaitu mengetahui dan menggunakannya dengan baik selama proses desain diperoleh persentase sebesar $22,06 \%$.

Selanjutnya, berdasarkan pemahaman terhadap konsep PBBD, peneliti mengelompokkan pemahaman responden berdasarkan karakteristik pengalaman dalam mendesain bangunan residensial bertingkat tinggi di kota Surabaya. Hasil tersebut ditunjukkan pada Gambar 2-5.

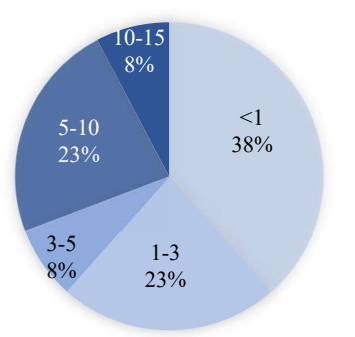

Gambar 2. Presentase pengalaman responden yang belum mengetahui konsep PBBD

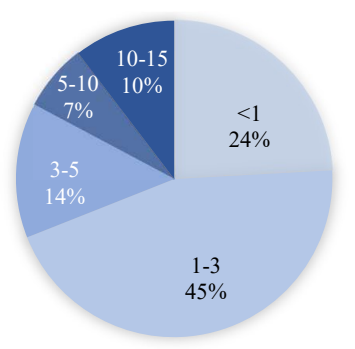

Gambar 3. Presentase pengalaman responden yang mengetahui konsep PBBD 


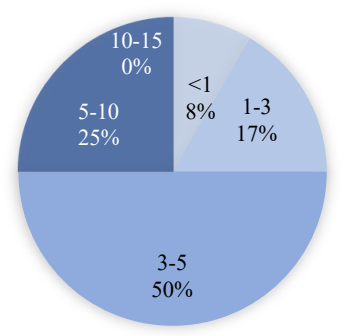

Gambar 4. Presentase pengalaman responden yang mengetahui, namun belum pernah menerapkan pada proses desain

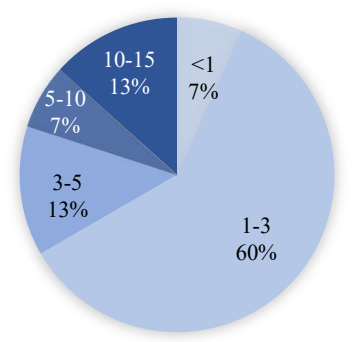

Gambar 5. Presentase pengalaman responden yang mengetahui dan menggunakan dalam proses desain

Berdasarkan Gambar 2-5 yaitu karakteristik pengalaman responden dalam memahami PBBD, ditemukan pada Gambar 2 hampir sebahagian besar responden yang belum mengetahui konsep PBBD memiliki pengalaman $<1$ tahun dalam mendesain bangunan (38\%). Penelitian ini menunjukkan bahwa pentingnya pengalaman bagi pelaku desain akan secara langsung memiliki pengaruh terhadap pemahaman perancang dalam mendesain, seperti yang ditunjukkan pada Gambar 3-5 yakni responden yang mengetahui konsep PBBD memiliki pengalaman rata-rata $>3$ tahun. Yang menarik dari temuan penelitian ini adalah praktik penggunaan konsep PBBD, yaitu pelaku desain yang memahami PBBD namun belum menggunakannya pada proses desain justru perancang yang mayoritas memiliki pengalaman dalam mendesain 5 tahun (50\%), sedangkan perancang yang memahami PBBD dan menggunakan pendekatan ini dalam praktik desainnya adalah perancang dengan pengalaman 3 tahun $(60 \%)$.

Penerapan PBBD tidak terlepas dari penggunaan teknologi selama proses mendesain bangunan berkinerja tinggi yang telah mendukung permodelan desain menjadi praktik yang canggih. Sebagai contoh yaitu penggunaan Building Information Modeling (BIM) yang berguna dalam pertukaran informasi desain yang dibuat antar perancang multidisiplin [11]. Penggunaan teknologi ini tentunya memberikan kebermanfaatan bagi pelaku desain, namun sayangnya penggunaan BIM di Indonesian tergolong masih rendah bagi kalangan praktisi [17], sehingga secara langsung akan memberikan efek terhadap praktik penerapan PBBD. Disamping itu, proses PBBD juga membutuhkan spesifikasi kinerja yang hanya dapat dikerjakan oleh perancang spesialis, maka kebutuhan untuk melibatkan tim desain multidisiplin dalam berkolaborasi selama proses desain berguna untuk menerjemahkan persyaratan kinerja ke dalam desain bangunan [5]. Kenyataannya, praktik kolaborasi yang dilakukan selama proses desain tidak mudah, masih terdapat kekhawatiran yang dirasakan oleh konsultan desain terhadap prosesnya. Kekhawatiran tersebut dikarenakan seringkali pekerjaan desain saling bergantung satu sama lain, sehingga sulit untuk mencapai desain yang terintegrasi [6].

Dengan strategi perancangan yang baik, penggunaan PBBD dapat meningkatkan keuntungan bagi pemilik bangunan selama masa operasionalnya [10]. Selain itu menggunakan konsep PBBD akan memberikan arahan dalam menghasilkan bangunan berkelanjutan yang sehat dan aman bagi pengguna akhir yaitu penghuni gedung [8]. Bangunan berkinerja tinggi atau bangunan berkelanjutan merupakan tahapan untuk membangun masa depan. Tidak hanya pada proses desainnya, namun bangunan berkelanjutan adalah tentang proses bagaimana bangunan beroperasi dan memberikan manfaat terhadap lingkungan. Apalagi telah diyakini bahwa kegiatan konstruksi adalah penyumbang terbesar yang berdampak terhadap lingkungan selama fase konstruksi dan fase operasional. Dengan meningkatnya kesadaran dan pemahaman tentang dampak-dampak ini, berbagai upaya terus dilakukan untuk menghindari efek buruk yang terjadi, salah satu contohnya adalah pemilihan dan spesifikasi bahan yang sesuai. Pemahaman arsitek dan kesadarannya terhadap lingkungan dalam memilih dan menentukan bahan pada tahap desain akan berpengaruh selama proses konstruksi [16].

\section{Simpulan}

Penelitian ini bertujuan untuk mengetahui tingkat pemahaman pelaku desain mengenai performance-based building desain (PBBD) pada proses desain residensial bertingkat tinggi. Mencapai tujuan ini, alat instrumen data berupa kuisioner dibagikan kepada konsultan desain di Surabaya yang pernah atau sedang terlibat pada proses mendesain properti residensial bertingkat tinggi di kota Surabaya. Hasil penelitian menunjukkan bahwa pelaku desain umumnya telah mengetahui konsep PBBD, namun penerapannya pada proses desain masih sangat rendah. Hal ini mendorong penerapan praktik PBBD membutuhkan dukungan dari berbagai pemangku kepentingan terkait yang terlibat di sektor konstruksi. 
Penelitian ini memberikan implikasi manajerial yaitu dengan mengetahui dan menggunakan konsep PBBD pada proses perencanaan dan perancangan bangunan residensial bertingkat tinggi akan berkontribusi terhadap pembangunan gedung yang sehat dan aman bagi pengguna/ penghuni gedung. Selain itu, menggunakan pendekatan ini juga memungkinkan pelaku desain dapat meningkatkan hubungan diantara tim desain selama pengembangan proyek, karena terjalinnya kesamaan persepsi dan kolaborasi yang baik. Penelitian ini juga membutuhkan penelitian lebih lanjut mengenai proses pengelolaan PBBD pada tahapan desain dan hubungannya dengan faktor kesuksesan desain.

\section{Daftar Pustaka}

[1] E. Bernardini, S. M. J. Spence, D.-K. Kwon, and A. Kareem, "Performance-Based Design of High-Rise Buildings for Occupant Comfort," J. Struct. Eng., vol. 141, no. 10, p. 04014244, 2015.

[2] L. O. Oyedele and K. W. Tham, "Clients' assessment of architects' performance in building delivery process: Evidence from Nigeria," Build. Environ., vol. 42, no. 5, pp. 2090-2099, 2007.

[3] A. S. Ali, S. N. Kamaruzzaman, A. S. Zulkiflee, and M. R. Pitt, "A study of design performance of refurbishment projects in Malaysia," J. Asian Archit. Build. Eng., vol. 9, no. 2, pp. 323-329, 2010.

[4] J. Iwaro, A. Mwasha, R. G. Williams, and W. Wilson, "The role of integrated performance model in sustainable envelope design and assessment," Int. J. Sustain. Eng., vol. 8, no. 4-5, pp. 294-316, 2015.

[5] R. Becker, "Fundamentals of performance-based building design," Build. Simul., vol. 1, no. 4, pp. 356371, 2008.

[6] Y. Rahmawati, C. Utomo, N. Anwar, C. B. Nurcahyo, and N. P. Negoro, "Jurnal Teknologi Theoretical Framework of Collaborative Design Issues,” vol. 7, pp. 47-53, 2014.

[7] X. Shi, "Performance-based and performance-driven architectural design and optimization," Front. Archit. Civ. Eng. China, vol. 4, no. 4, pp. 512-518, 2010
[8] X. Zhao, W. Li, and J. Stanbrook, "A framework for the integration of performance based design and life cycle assessment to design sustainable structures," Adv. Struct. Eng., vol. 17, no. 4, pp. 461-470.

[9] B. C. Ertanto, I. Satyarno, and B. Suhendro, "Performance Based Design Bangunan Gedung Untuk Level Kinerja Operasional," Perform. Based Des. Bangunan Gedung Untuk Lev. Kinerja Oper., vol. 13, no. 2, pp. 189-204, 2017.

[10] S. D. Astarini, C. Utomo, A. F. Sari, M. A. Rohman, and N. P. Negoro, "The influence of performancebased building design on the strategy of retail property in indonesia," Sustain., vol. 12, no. 21, 2020.

[11] V. Machairas, A. Tsangrassoulis, and K. Axarli, "Algorithms for optimization of building design : A review," vol. 31, no. 1364, pp. 101-112, 2014.

[12] A. Engebø, O. J. Klakegg, J. Lohne, R. A. Bohne, H. Fyhn, and O. Lædre, "High-performance building projects: how to build trust in the team," Archit. Eng. Des. Manag., vol. 0, no. 0, pp. 1-17, 2020.

[13] J. van Hoof, P. G. S. Rutten, C. Struck, E. R. C. M. Huisman, and H. S. M. Kort, "The integrated and evidence-based design of healthcare environments," Archit. Eng. Des. Manag., vol. 11, no. 4, pp. 243-263, 2015.

[14] Priyono, Metode Penelitian Kuantitatif, Revisi. Sidoarjo, Jawa Timur: Zifatama Publishing, 2008.

[15] A. Lundström, J. Savolainen, and E. Kostiainen, "Case study: developing campus spaces through cocreation," Archit. Eng. Des. Manag., vol. 12, no. 6, pp. 409-426, 2016.

[16] C. J. Kibert, Sutainable Construction : Green Building Design and Delivery, 4th ed. Hoboken, New Jersey: John Wiley \& Sons, 2016.

[17] Y. Hanifah, "Awareness dan Pemanfaatan BIM : Studi Eksplorasi," Temu Ilm. IPLBI 2016, no. August, pp. 49-54, 2016, [Online]. Available: http://temuilmiah. iplbi.or.id/awareness-dan-pemanfaatan-bim-studieksplorasi/. 
